\title{
Reviews
}

\section{Snapping Hip Syndrome: A Comprehensive Update}

\author{
Paul Walker, BS ${ }^{1}$ a , Emily Ellis, BS ${ }^{2}$, John Scofield, BS ${ }^{2}$, Thaksin Kongchum, BS ${ }^{2}$, William F. Sherman, MD, MBA ${ }^{3}$, Alan D. \\ Kaye, MD, $\mathrm{PhD}^{2}$ \\ ${ }^{1}$ Weill Cornell Medical College, ${ }^{2}$ School of Medicine, Louisiana State University Health Science Center Shreveport, ${ }^{3}$ Department of Orthopaedic \\ Surgery, Tulane University \\ Keywords: iliotibial tendon, iliopsoas tendon, hip arthroscopy, snapping hip syndrome, coxa saltans \\ https://doi.org/10.52965/001c.25088
}

\section{Orthopedic Reviews}

Vol. 13, Issue 1, 2021

\section{Purpose of review}

This is a comprehensive literature review regarding the pathogenesis, diagnosis, and treatment of snapping hip syndrome (SHS). It covers the diverse etiology of the syndrome and management steps from conservative to more advanced surgical techniques.

\section{Recent Findings}

Recent advances in imaging modalities may help in diagnosing and treating SHS. Additionally, arthroscopic procedures can prove beneficial in treating recalcitrant cases of SHS and have recently gained popularity due to their non-invasive nature.

\section{Summary \\ SHS presents as an audible snap due to anatomical structures in the medial thigh compartment and hip. While often asymptomatic, in some instances, the snap is associated with pain. Its etiology can be broadly classified between external SHS and internal SHS, which involve different structures but share similar management strategies. The etiology can be differentiated by imaging and physical exam maneuvers. Treatment is recommended for symptomatic SHS and begins conservatively with physical therapy, rest, and anti-inflammatory medications. Most cases resolve after 6-12 months of conservative management. However, arthroscopic procedures or open surgical management may be indicated for those with persistent pain and symptoms. Different surgical approaches are recommended when treating internal SHS vs. external SHS. Due to advancements in treatment options, symptomatic SHS commonly becomes asymptomatic following intervention.}

\section{INTRODUCTION}

Snapping hip syndrome (SHS), alternatively known as "coxa saltans," is a condition characterized by an audible or palpable snap of the hip joint. ${ }^{1}$ The phenomenon can be bilateral or unilateral, painful or painless, idiopathic, or posttraumatic. SHS is due to "snapping" of the iliopsoas tendon or the iliotibial band. The iliopsoas variant, referred to as the internal type, can be reproduced by extending and internally rotating a flexed, abducted, and externally rotated hip. ${ }^{2}$ The iliotibial variant, which is the external type, is due to the iliotibial band sliding over the greater trochanter, posteriorly to anteriorly, when the hip is moved from extension to flexion. ${ }^{2}$ These two pathologies (internal and external) are mutually described as "extra-articular.” Snapping hip can also occur due to intra-articular pathologies (loose body, torn labrum, fracture), which are generally more harmful than extra-articular. ${ }^{3}$ Intra- and extra-articular pathologies can co-exist, particularly with the iliopsoas variant of SHS. ${ }^{1}$ Most treatment regimens begin with conservative options, involving NSAIDs, physical therapy, activity modification, and ice therapy. If symptoms persist, corticosteroid injections or surgery may be indicated. ${ }^{3}$ The purpose of this review is to provide a comprehensive update

\footnotetext{
a Corresponding author:

Paul Walker

Weill Cornell Medical College

1300 York Ave

New York, NY, 10065

Phone: (951) 375-2109

pbw4001@med.cornell.edu
} 
on the etiology, pathogenesis, and management of SHS.

\section{METHODS}

A review of the current literature was performed in PubMed, Google Scholar, Embase, and Medline from January 1, 1975, to May 31, 2021. Search terms included snapping hip syndrome, coxa saltans, iliopsoas muscle, and iliotibial band. We sought to identify reviews, prospective, retrospective, and original studies. Analysis was performed to elucidate further the etiology, pathophysiology, diagnostic management, and treatment of SHS.

\section{EPIDEMIOLOGY, PATHOPHYSIOLOGY, AND RISK FACTORS}

\section{EPIDEMIOLOGY}

SHS occurs as an incidental finding in roughly $5-10 \%$ of all people. ${ }^{1,2}$ There are no significant differences between sexes regarding external SHS rates. ${ }^{1}$ However, more females are diagnosed with internal (iliopsoas) SHS than males. This is possibly due to women having higher rates of specific hip pathologies than men, such as hip dysplasia. ${ }^{4}$

\section{CLINICAL PRESENTATION AND RISK FACTORS}

SHS can be painless or painful, acute or chronic, but invariably affects a degree of hip mobility. ${ }^{5}$ Symptomatic patients typically include those who perform tasks requiring frequent movement of the hip and/or consistent extreme rotations of the hip.

While the pathophysiology of SHS remains unclear, the pathology is usually considered to be multifactorial. Young athletes, especially those who are skeletally immature, are deemed to be at risk. The risk is compounded when participating in a sport or event that involves frequent hip rotation. As such, SHS is most notably observed in gymnastics and ballet. ${ }^{6}$ A cross-sectional study of 87 elite ballet dancers showed that $91 \%$ of this population had some degree of SHS. ${ }^{4,7}$ SHS is the third most common hip pathology in young women. The higher rates of hip injuries in young females are possibly due to the size and growth of female pelvises during development.

Common risk factors for internal SHS include a hypertrophied psoas muscle and inflammation of the psoas muscle due to trauma. Dancers, gymnasts, individuals who exercise avidly, and overweight and obese patients are most at risk for a hypertrophied psoas muscle. ${ }^{1}$ Trauma specifically related to internal SHS is inflammation in areas of the internal hip, such as the iliopsoas bursa, iliopsoas muscle, and other local structures.

Risk factors for external SHS are similar to internal SHS. Repetitive action is the most common risk factor. It occurs in those who run or jog, especially on sloped surfaces such as hills. The posterior iliotibial tendon and/or the anterior portion of the gluteus maximus become hypertrophied, which increases friction as they attempt to glide past one another. ${ }^{2}$ Athletes also may have hypertrophied gluteus maximus and tensor fascia lata muscles, which could potentially increase the tension of the iliotibial band. This leads to a decrease in space for tendon excursion. ${ }^{8}$ External SHS can also be due to an iatrogenic cause, especially in those with their iliotibial band used for grafts. Idiopathic anatomical causes that lead to outward bulging of the greater trochanter have also been mentioned in the literature. ${ }^{2,9}$

\section{PATHOPHYSIOLOGY}

The etiology of SHS can be categorized into two categories: intra-articular and extra-articular. Extra-articular is then subdivided into external and internal types. ${ }^{5,10,11}$ Intra-articular snapping can be caused by muscle tears, muscle damage, and loose bodies.5,10,11 Extra-articular internal snapping is usually caused by the movement of the iliopsoas tendon over a bone, such as the femoral head or the lesser trochanter.5,12,13 Extra-articular external snapping usually occurs from the movement of the iliotibial band or the tendon of the gluteus maximus over the greater trochanter. ${ }^{7,10,11,14,15}$

The internal, or iliopsoas, type of SHS often produces an audible pop. ${ }^{2}$ The pop occurs as the iliopsoas tendon encounters a hindrance while moving from the lateral to the medial position. As the iliopsoas tendon moves, the hip extends and internally rotates. ${ }^{2}$ The femoral head seems to be the most common anatomic structure that hinders the iliopsoas tendon. ${ }^{1}$ The femoral head engages in a complex interplay with the iliacus muscle, iliopsoas bursa, iliofemoral ligament, pubic bone, iliopectineal eminence, and the iliopsoas muscle. When the hip is extended, the iliopsoas tendon may wedge itself medially due to the femoral head or pectineal eminence of the pelvis. ${ }^{1,2,8}$ Another theory involves the iliopsoas bursa, which lies anterior to the iliopectineal eminence and posterior to the musculotendinous portion of the iliopsoas muscle. The bursa extends proximally into the iliac fossa and distally to the lesser trochanter. It is the largest synovial bursa in the body. In some SHS presentations, the synovial bursa could serve as the largest or sole impediment in the medial movement of the iliopsoas tendon. ${ }^{8}$ It has also been theorized that the pop occurs as the iliopsoas tendon transverses an outgrowth of the lesser trochanter. Regardless, the iliopsoas tendon is conspicuously taut with the hip extended, contributing to anatomical congestion in the inguinal and pelvic regions. $^{2}$ The internal type of SHS is likely to be multifactorial.

The external, or iliotibial, type of SHS is usually inaudible, but there is often a visual component to the snap that the patient may observe. ${ }^{2}$ This snap occurs as the iliotibial band slides from the posterior aspect of the greater trochanter to the anterior aspect. This particular movement of the iliotibial band occurs as the hip moves from an extended to a flexed position. In some patients, friction may occur between the iliotibial band and the greater trochanter during this sliding movement, which produces a snapping sensation. Thickening of the posterior iliotibial band and/or thickening of the anterior gluteus maximus muscle is considered to cause excess friction. ${ }^{2,16}$ In external SHS, the iliotibial band, remains taut due to its proximal muscular attachments (tensor fascia lata anteriorly; gluteus maximus posteriorly) and its distal bony attachments (posterior femur, lateral tibia, lateral retinaculum) $.8,17$ The increased 
Table 1. Physical exam maneuvers

\begin{tabular}{|c|c|}
\hline Internal SHS & External SHS \\
\hline $\begin{array}{l}\text { Ober } \\
\text { The patient is lying on the non-painful side and raising the knee up } \\
\text { and down with the knee at a right angle. }\end{array}$ & $\begin{array}{l}\text { Thomas test \& Modified Thomas } \\
\text { The patient lies supine and pulls the unaffected knee to the chest. }\end{array}$ \\
\hline $\begin{array}{c}\text { FABER } \\
\text { flexion, abduction, and external rotation } \\
\text { Active flexion followed by passive extension and abduction in lateral } \\
\text { decubitus }\end{array}$ & $\begin{array}{l}\text { Stinchfield test } \\
\text { The patient lies supine and with hip at } 30^{\circ} \text { and is asked to fully flex } \\
\text { the hip against resistance. }\end{array}$ \\
\hline $\begin{array}{l}\text { Hula-Hoop } \\
\text { The patient is standing with adduction with circumduction of the } \\
\text { affected hip. }\end{array}$ & $\begin{array}{l}\text { lliopsoas test } \\
\text { Movement from flexion, abduction, and external rotation to } \\
\text { extension, adduction, and internal rotation in supine decubitus }\end{array}$ \\
\hline
\end{tabular}

tension contributes to the snapping sensation, as it limits space for smooth translation of the tendon. The snapping sensation is palpable and can be mitigated by applying pressure. $^{2}$

The intra-articular type of SHS is a pathological process of the hip joint itself. The most common causes are loose bodies, acetabular labrum tears, or osteochondral fractures. ${ }^{3}$ Loose bodies, such as pieces of bone or cartilage, can interfere with articulating the femoral head into the acetabulum. Acetabular labrum tears can displace the head of the femur, preventing it from being securely situated inside the acetabulum. An osteochondral fracture disrupts the integrity of the femoral head, preventing smooth articulation into the acetabulum. All of the causes of intra-articular lesions share similar characteristics. First, the sensation is more related to a clicking sensation than a snapping sensation. Second, the main complaint will likely be pain. Lastly, intra-articular lesions are commonly associated with trauma, leading to a rapid onset. Therefore, obtaining comprehensive trauma history is essential in establishing this diagnosis. $^{8}$ If an intra-articular pathology were confused with an extra-articular lesion, it would almost certainly be the internal type since the iliotibial band is anatomically distant from the inguinal area. ${ }^{8}$

\section{DIAGNOSIS}

Medical history and physical examination are the primary diagnostic methods for snapping hip syndrome. ${ }^{10,18}$ However, imaging can help determine the specific type of SHS. Despite its primarily painless presentation, a diagnosis needs to be made promptly to help prevent the onset of pain and eventual changes in hip mobility.

Table 1 summarizes physical exams maneuvers that are useful in diagnosing and differentiating SHS. ${ }^{1}$

Imaging modalities to identify SHS include Magnetic Resonance Imaging (MRI), ultrasound, and x-ray. ${ }^{5,12}$ Imaging typically shows an enlargement of the affected muscle. ${ }^{5,11,12,19}$ In addition, imaging may also include or exclude other known causes of internal snapping pain, such as iliopsoas tendonitis. ${ }^{7,14,15} \mathrm{X}$-rays can help examine the hip joint and pelvis anatomy, especially in situations where the snap is associated with acetabular anteversion, femoroacetabular impingement, or developmental dysplasia. ${ }^{1}$ Dynamic ultrasound can be used to show the tendon moving over the bone. $7,12,14,15,19$ This has proven helpful as hip muscle movement is often required to elicit the snap. $., 10,11$ Real-time dynamic ultrasound can also address discernible causes such as loose bodies. ${ }^{10,20}$ The supplementation of MRI or CT helps determine the underlying cause of SHS. ${ }^{12,19}$ Specifically, for external SHS, MRI findings typically include hypertrophied gluteus maximus or tight iliotibial band (ITB). Those with a tense ITB were more likely to have a reversible condition and shorter symptom duration. $^{21}$

\section{TREATMENT AND MANAGEMENT INTRO AND OVERVIEW}

The management of SHS is similar across all etiologies. Once identified, a regime should be adopted that ranges from stretching and lifestyle changes to avoid overuse of the affected muscles to surgical intervention.

\section{CONSERVATIVE/MEDICAL MANAGEMENT}

Conservative management is the first line for treating symptomatic snapping hip syndrome as it has a high success rate with very low risk. ${ }^{22}$ Though the origins of SHS may vary, conservative management follows a similar methodology: an emphasis on rest, stretching, physical therapy, and anti-inflammatory medication targeted towards affected muscle tendons.

The first step in managing patients suspected of SHS is to thoroughly examine the patient to identify the underlying origin. ${ }^{23-25}$ Patient mobility, palpation around the entire joint, and gait analysis identify any movement issues and confirm SHS. ${ }^{23-25}$ Functional movements can be used to determine the severity of those issues. ${ }^{23,24}$ Range of motion should be assessed if intra-articular SHS is suspected using the FADIR test (flexion, adduction, and internal rotation or impingement). ${ }^{25}$

Rest and avoidance of any activity thought to induce snapping are of utmost importance.4,15,26-28 Minimizing activity allows the muscles to heal, thereby alleviating pain. Patient-Physician education and communication are also critical in helping patients adapt to a new lifestyle. To maintain muscle strength during rest, patients can engage in activities that reduce strain and heavy use of the hip; practical 
examples include cross-training exercise or water exercise. $^{22}$ Non-steroidal anti-inflammatory drugs (NSAIDs) should be prescribed to relieve the inflammation caused by friction between the tendon and another internal pelvic structure. 15,26,27 Physical therapy with an emphasis on physiotherapy is an integral part of a conservative management regime. This may include deep massage, myofascial release, core stability, and pelvic stabilization exercises. ${ }^{1,20}$ Stretching exercises naturally lengthen the affected tendon, allowing muscles or the bones to lose contact with the tendon during hip movement. ${ }^{25,29}$ Spina et al. reported complete resolution of symptoms in one patient after applying Active Release Technique (ART) to the lateral hip complex. ART is a non-invasive soft tissue treatment that reduces tension by removing fibrosis and adhesions in the area of interest. ${ }^{30}$

If rest, physical therapy, and NSAIDs do not provide relief, more advanced procedures may be performed. Anesthetic and corticosteroid injections into the involved bursa or tendon sheath can provide pain relief, in addition to being a valuable diagnostic tool in differentiating between internal and external SHS. ${ }^{14,15,26,27,31-33}$ If there is relief with injection into the iliopsoas bursa, the patient most likely has internal SHS. Conversely, if relief follows injection into the hip joint itself, the patient most likely has an intra-articular pathology. ${ }^{4}$ Anesthetic mixtures, such as a Bupivacaine/Lidocaine combination, have successfully treated recalcitrant SHS. ${ }^{14}$ Fluoroscopy, ultrasound, and computed tomography are often utilized to help visualize the desired site of injection. ${ }^{20,32,34}$ Non-guided injections are less accurate; however, there was no significant difference in clinical effectiveness between guided or not. 35,36 These methods are considered first-line and usually provide symptomatic relief for most patients. ${ }^{4,15}$

\section{MINIMALLY INVASIVE MANAGEMENT}

Surgery is considered if there is no improvement after twothree months of physical therapy and conservative management. ${ }^{37,38}$ Compared to open surgery, minimally invasive endoscopic treatments have better results, including fewer complications, failure rates, and postoperative pain. ${ }^{1}$

\section{EXTERNAL SNAPPING HIP SYNDROME}

A variety of minimally invasive procedures have been described in treating external SHS, including endoscopic iliotibial band release, endoscopic gluteus maximus tendon release, and dextrose prolotherapy. 1,39

Iliotibial band release is an outpatient surgery that allows patients to return home on the same day of surgery. It can be performed in an open fashion as well as endoscopically. Two ports are inserted superior and inferior to the greater trochanter with the patient in the lateral decubitus position for patients undergoing endoscopic release. ${ }^{40} \mathrm{To}$ release the iliotibial band and relieve tension, multiple incisions are made through the iliotibial band. ${ }^{1}$ White et al. used a $10 \mathrm{~cm}$ longitudinal incision with six evenly spaced transverse step cuts, each $1.5 \mathrm{~cm}$. With this technique, 14 out of 16 patients returned to their previous activity level with no lingering symptoms following the procedure. Two patients had a recurrence and required a second release..$^{40}$ Kunac et al. used a similar approach with a $10 \mathrm{~cm}$ longitudinal cut and three $3 \mathrm{~cm}$ perpendicular cuts. Both patients returned to full sporting activities within six weeks and had no hip snapping or pain following the procedure. Ilizaliturri et al. used an alternative cross-shaped cut and resected a diamond-shaped segment of the iliotibial band. ${ }^{41}$ With this technique, 10 out of 11 patients returned to their previous activity level with no complaints. One patient reported improvement but noted non-painful snapping following the procedure. $^{41}$

Gluteus maximus tendon release is an alternative outpatient procedure described by Polesello et al. Due to concerns about endoscopic iliotibial band release altering the shape of the lateral thigh and overloading the contralateral abduction mechanism, Polesello et al. introduced a novel technique that does not cause deformity over the thigh. This procedure is performed endoscopically with the patient under general anesthesia in the supine position. The femoral insertion of the gluteus maximus tendon is visualized with an arthroscope using superior and inferior trochanteric portals. Once visualized, the gluteus maximus tendon is transected using a radiofrequency device. With this technique, eight out of eight patients returned to their previous level of activity. However, one patient required a revision procedure because his snapping and pain persisted after surgery. This patient was asymptomatic after the revision procedure. ${ }^{38}$ While the Polesello technique spares deformity of the lateral thigh, residual gluteal hypotrophy and asymmetry have been reported in a few studies using the Polesello technique. ${ }^{42}$

For endoscopic release, Malinowski et al. described a fanlike technique that allows the surgeon to gradually incise structures intraoperatively until snapping is eliminated. ${ }^{43}$ The aim is to avoid total release and tissue removal, except in the case of an inflamed trochanteric bursa. Advantages to this approach include a staged procedure tailored to the patient and direct visualization. Disadvantages include increased duration and difficulty, the risk for excessive hematoma with accidental incision, risk of iatrogenic injury to the sciatic nerve and gluteal vessels, and possible buttocks asymmetry. ${ }^{43}$

Ultrasound-guided dextrose prolotherapy is another minimally invasive technique described by Hung et al. Ultrasound guidance is used to visualize the iliotibial band and gluteus medius tendon. $1.5 \mathrm{~mL}$ of $25 \%$ dextrose solution is injected into the space between the iliotibial band and gluteus medius tendon to reduce swelling and dilate the intertendinous space. In the case study described by Hung et al., the patient returned to previous level activity with no pain or snapping after two cycles of dextrose injections. ${ }^{39}$

\section{INTERNAL SNAPPING HIP SYNDROME}

A variety of minimally invasive procedures have also been described for the treatment of internal snapping hip syndrome. These include fractional iliopsoas lengthening, iliopsoas tendon release, and ultrasound-guided hydrodilation. ${ }^{44-46}$

Endoscopic release of the iliopsoas tendon is an outpatient procedure. It is performed endoscopically with the pa- 
tient under general anesthesia in the supine position. ${ }^{47}$ It can be performed at the lesser trochanter or the hip joint with transcapsular release. Due to the proximity of lesser trochanter to femoral neurovascular structures, the lesser trochanter approach is thought to have greater risk than the transcapsular approach. ${ }^{48}$ Patel et al. and Ilizaliturri et al. describe a case series of ten and six patients, respectively. The lesser trochanter approach yielded no complications apart from the loss of flexion strength that improved by eight weeks after the procedure. ${ }^{41,48}$ Hwang et al. had good results with the transcapsular approach in 24 out of 25 patients, all of whom had lost flexion strength postoperatively for six weeks. All patients returned to their previous activity level within ten weeks, and 24 out of 25 patients noted improvement. Ilizaliturri et al. conducted a randomized control trial of 19 patients comparing endoscopic iliopsoas tendon release at the greater trochanter $(n=10)$ to endoscopic transcapsular psoas release from the peripheral compartment $(n=9)$. No difference in perioperative complications and postoperative outcomes were found between the two groups. ${ }^{49}$ Ilizaliturri et al. also conducted a randomized control trial of 20 patients comparing endoscopic iliopsoas release at the lesser trochanter $(n=6)$ to endoscopic iliopsoas release from the central compartment $(\mathrm{n}=14)$. In both groups, all patients noted improvement in symptoms, and no complications were reported. However, one patient in the central compartment release group had a recurrence of snapping that required a revision procedure. 50

Endoscopic iliopsoas fractional lengthening is an alternative procedure for the treatment of internal SHS. It is performed with the patient in the supine position with standard anterolateral, mid-anterior, and distal anterolateral portals. Once the iliopsoas tendon is visualized, fractional lengthening is completed in which the tendon is $50 \%$ tendon and $50 \%$ muscle. ${ }^{51}$ El Bitar et al. demonstrated complete resolution of painful snapping in 45 out of 55 patients using this technique. The recurrence of painful snapping hip was higher compared to studies using the endoscopic iliopsoas tendon release technique. ${ }^{44}$

Ultrasound-guided hydrodilation of the space between the iliopsoas tendon and iliacus muscle is another approach described by Chang et al. In this approach, a mixture of 5 $\mathrm{mL}$ of $50 \%$ dextrose and $5 \mathrm{~mL}$ of $1 \%$ lidocaine is injected between the iliacus muscle and iliopsoas tendon to reduce the tension on the iliopsoas tendon during hip extension. In a case of a 42-year-old male jogger, ultrasound-guided hydrodilation immediately improved snapping and pain, and there was no recurrence at three-month follow-up. ${ }^{46}$

Villanueva et al. recently reported on an ultra-minimally invasive technique for SHS. They used continuous ultrasound guidance to make a z-plasty or transverse section of the ITB. ${ }^{52}$ The novel technique was performed in 14 patients, all of whom reported complete resolution of pain and snapping at a 1-year follow-up. Other than minor hematomas, no complications were reported.

\section{OPEN SURGICAL MANAGEMENT}

If SHS fails both conservative and minimally invasive management, open surgical techniques are indicated. Endo- scopic surgical management yields lower recurrence rates, smaller incisions, less postoperative pain, and lower complication rates than open surgical management. However, in comparing open to endoscopic surgical management, it is essential to note the limited sample size for endoscopic surgeries. ${ }^{42,53-55}$

\section{EXTERNAL SNAPPING HIP SYNDROME}

Open surgical management of external SHS primarily targets the iliotibial band to prevent sliding over the greater trochanter. Various open surgical procedures have been described, including resection of the iliotibial band and lengthening of the iliotibial band (Z-plasty). ${ }^{55}$

Resection of the iliotibial band is an open surgical procedure performed under general anesthesia. The iliotibial band can be resected at several sites. ${ }^{55}$ Larsen et al. performed resection of the posterior half of the iliotibial band at the insertion site with the gluteus maximus. In 22 out of 31 hips, patients were pain-free with no snapping after the procedure. Snapping persisted in the other 9 cases, and in 3 of the 9 cases, snapping remained painful. ${ }^{56}$ Zoltan et al. performed resection of an ellipsoid-shaped segment of the iliotibial band over the greater trochanter. Four out of 7 patients had complete resolution of pain and snapping. One patient had persistent painful snapping after the procedure, with improvement after a revision procedure. Results for the other two patients were not reported. ${ }^{57}$

Open lengthening of the iliotibial band (Z-plasty) is more commonly performed for external snapping hip syndrome compared to resection of the iliotibial band. ${ }^{55}$ The patient is placed in the lateral decubitus position under general anesthesia. The tension of the gluteus maximus is released by creating a Z-incision in the iliotibial band. Zplasty lengthening is performed on the proximal one-third of the iliotibial band with a proximal and distal incision on the iliotibial band. The proximal incision is directed posteriorly, and the distal incision is directed anteriorly. ${ }^{58-60}$ Brignall \& Stainsby reported that five out of eight patients had complete resolution of snapping and remained painfree after the procedure. Two of the eight patients noted occasional pain over the greater trochanter with exercise, and the other patient required a revision procedure and reached a successful outcome. ${ }^{60}$ Faraj et al. used the technique described by Brignall \& Stainsby with an earlier postoperative return to weight-bearing and found seven out of 10 patients were pain-free with no snapping after the procedure. The other three patients noted painful scars and required desensitization treatment with massage, ultrasound, and heat therapy. ${ }^{59}$ Provencher et al. also used the technique described by Brignall \& Stainsby on seven military personnel. They found that six out of seven patients returned to their previous activity level with complete snapping and pain resolution. The other patient had complete resolution of snapping but had persistent groin pain. 58

Nam et al. noticed that it was challenging to ensure the adequate release of the gluteus maximus tension using the Brignall \& Stainsby technique. They described a modified technique in which ends of the Z-incision were transposed to the relaxed position when the hip was flexed and adducted. With this technique, the incision ends were sutured 
just enough to release the gluteus maximus tension. All 14 patients had complete resolution of pain and snapping and returned to their previous activity level within six months. No patients required revision surgery or had disease recurrence. 61

Sayed-Noor et al. chose to lengthen the iliotibial band at the distal end rather than lengthening the iliotibial band at the proximal end over the greater trochanter. It was thought that operating at the distal end would avoid inflicting further trauma to the greater trochanter. It was also less invasive. With this approach, all five patients had complete resolution of pain and snapping. There were no signs of recurrence or complications with the procedure. ${ }^{62}$

\section{INTERNAL SNAPPING HIP SYNDROME}

Open surgical management of internal SHS primarily targets the iliopsoas tendon to prevent sliding over the iliopectineal eminence. Various open surgical techniques have been described, including open transection of the iliopsoas tendon and open iliopsoas tendon lengthening. The overall success of open surgical procedures in internal SHS is $77 \% .54$

Taylor \& Clark initially described open transection of the iliopsoas tendon at the level of the lesser trochanter was initially described by Taylor \& Clark. This procedure is performed under general anesthesia with a $5 \mathrm{~cm}$ horizontal incision below the inguinal skin crease. The iliopsoas tendon is identified, and the tendinous portion is divided, leaving the muscle fibers intact. Using this technique, 10 out of 14 patients had pain resolution, and eight out of 14 decreased in pain compared to before the procedure. Of the six patients with a postoperative snap, five noted improvements in snap frequency compared to before the procedure, and one noted no improvement. 63

Open fractional lengthening of the iliopsoas tendon is considered a more effective procedure than open transection of the iliopsoas tendon at the lesser trochanter. However, it has a higher rate of postoperative pain and loss of hip flexion strength. ${ }^{54}$ It is performed under general anesthesia with the patient in the supine position with an 8-10 $\mathrm{cm}$ incision made in the groin. The incision is bordered medially by the femoral canal and laterally by the lateral femoral cutaneous nerve. The iliopsoas tendon is identified and confirmed by palpating its insertion onto the lesser trochanter. The tendinous portion is divided proximally with $1 \mathrm{~cm}$ incisions every $2 \mathrm{~cm}$, leaving the muscle fibers intact. The identified tendon fibers are transected with caution to avoid the lateral femoral cutaneous nerve and femoral nerve. ${ }^{64,65}$

Dobbs et al. performed open fractional lengthening of the iliopsoas tendon on nine adolescents with an iliofemoral incision. All patients returned to their previous activity level, and eight out of nine had no recurrence of snapping. One patient noted recurrence but noted overall improvement. Two patients had transient numbness in the anterolateral aspect of the thigh, possibly due to irritation of the lateral femoral cutaneous nerve. ${ }^{64}$

Gruen et al. performed open fractional lengthening of the iliopsoas tendon on 11 patients with an ilioinguinal incision. All patients had complete resolution of snapping. 9 out of 11 patients had complete resolution of pain. Two patients noted "unsatisfactory" pain relief. One of these two patients returned to her previous level of activity. The other patient had multiple unsuccessful revision surgeries. ${ }^{66}$

Hoskins et al. performed open fractional lengthening of the iliopsoas tendon on 92 hips with an iliofemoral incision. Six patients reported persistent pain. Twenty patients reported recurrent snapping. Three patients reported flexor weakness. Eleven patients reported wound problems. Overall, 32 out of 92 patients experienced complications, including recurrent pain and snapping, anterior thigh paresthesia, transient hip flexor weakness, painful bursa formation, and superficial infection. However, there was an $89 \%$ patient satisfaction rate despite complications. 65

Komarasamy et al. performed open fractional lengthening of the iliopsoas tendon using an approach that minimized exposure to major neurovascular structures by staying close to the bone. Seven out of seven patients had complete resolution of painful snapping with surgery. Two of seven patients had slight hip flexion weakness immediately after surgery that resolved without intervention. One patient had transient numbness in the lateral thigh that resolved without intervention. ${ }^{67}$

\section{CONCLUSION}

Snapping hip syndrome is a primarily asymptomatic hip disorder characterized by a snapping sound or sensation upon specific hip joint movements. It has a diverse set of etiologies classified based on the anatomical structure causing the snapping sensation. Extra-articular snapping hip syndrome (SHS) comprises two main classes: external SHS, involving the iliotibial tendon, and internal SHS, involving the iliopsoas tendon. ${ }^{2}$ It is important to distinguish extra-articular SHS from intra-articular pathologies. Intraarticular processes are generally more acute, trauma-related, and largely more painful and debilitating.

Internal (iliopsoas) snapping is typically audible, while external (iliotibial) snapping is usually palpable and visible. ${ }^{1,2}$ The etiologies are multifactorial, and both present with a broad spectrum of symptoms, including pain and decreased mobility. The true prevalence remains unknown. However, it is estimated that roughly $5-10 \%$ of the population has some degree of SHS. Specific populations such as ballet dancers, avid runners, and gymnasts are more prone to develop this condition due to overuse and hypertrophy of involved anatomy. ${ }^{1,2}$ The most sensitive diagnostic tool is reproducing the snap with movement and physical exam. ${ }^{1}$ Dynamic ultrasound, MRI, X-ray, and CT scan can supplement the diagnosis and confirm the underlying cause. Symptomatic patients are usually managed with rest, physical therapy, NSAIDs, and corticosteroid injections or analgesics. If pain and snapping persist, endoscopic disengagement of the iliopsoas or iliotibial tendon is usually the source of relief. ${ }^{2}$

\section{AUTHOR CONTRIBUTIONS}

Sherman and Kaye conceived the topic of interest and were 
involved in planning and supervision. Walker performed a Submitted: June 08, 2021 EST, Accepted: June 17, 2021 EST comprehensive review of the literature and drafted the framework. Walker, Ellis, Scofield, Konchum, Sherman, and Kaye contributed to the writing and editing of the manuscript. 


\section{REFERENCES}

1. Giai Via A, Fioruzzi A, Randelli F. Diagnosis and Management of Snapping Hip Syndrome: A Comprehensive Review of Literature. Rheumatology. 2017;7(4). doi:10.4172/2161-1149.1000228

2. Byrd JWT. Snapping hip. Operative Techniques in Sports Medicine. 2005;13(1):46-54. doi:10.1053/j.ots m.2004.09.003

3. Badowski E. Snapping hip syndrome. Orthopaedic Nursing. 2018;37(6):357-360. doi:10.1097/nor.000000 0000000499

4. Lewis CL. Extra-articular snapping hip: A literature review. Sports Health. 2010;2(3):186-190. doi:10.1177/ 1941738109357298

5. Tibor LM, Sekiya JK. Differential Diagnosis of Pain Around the Hip Joint. Arthroscopy. 2008;24(12):1407-1421. doi:10.1016/j.arthro.2008.0 $\underline{6.019}$

6. Stracciolini A, Yen YM, D’Hemecourt PA, Lewis CL, Sugimoto D. Sex and growth effect on pediatric hip injuries presenting to sports medicine clinic. Journal of Pediatric Orthopaedics B. 2016;25(4):315-321. doi:1 $0.1097 / \mathrm{bpb} .0000000000000315$

7. Winston P, Awan R, Cassidy JD, Bleakney RK. Clinical examination and ultrasound of self-reported snapping hip syndrome in elite ballet dancers. Am J Sports Med. 2007;35(1):118-126. doi:10.1177/0363546 $\underline{506293703}$

8. Allen WC, Cope R. Coxa Saltans: The Snapping Hip Revisited. Journal of the American Academy of Orthopaedic Surgeons. 1995;3(5):303-308. doi:10.543 5/00124635-199509000-00006

9. Bellabarba C, Sheinkop MB, Kuo KN. Idiopathic hip instability: An unrecognized cause of coxa saltans in the adult. Clinical Orthopaedics and Related Research. 1998;355:261-271. doi:10.1097/00003086-19981000 $\underline{0-00028}$

10. Chang KS, Cheng YH, Wu CH, Özçakar L. Dynamic Ultrasound Imaging for the Iliotibial Band/Snapping Hip Syndrome. American Journal of Physical Medicine \& Rehabilitation. 2015;94(6):e55-e56. doi:10.1097/ph $\underline{\mathrm{m} .0000000000000299}$

11. Choi YS, Lee SM, Song BY, Paik SH, Yoon YK. Dynamic Sonography of External Snapping Hip Syndrome. Journal of Ultrasound in Medicine. 2002;21(7):753-758. doi:10.7863/jum.2002.21.7.753
12. Wunderbaldinger $\mathrm{P}$, Bremer C, Matuszewski L, Marten K, Turetschek K, Rand T. Efficient radiological assessment of the internal snapping hip syndrome. Eur Radiol. 2001;11(9):1743-1747. doi:10.1007/s00330 $\underline{0100886}$

13. Lee KS, Rosas HG, Phancao JP. Snapping hip: Imaging and treatment. Semin Musculoskelet Radiol. 2013;17(3):286-294. doi:10.1055/s-0033-1348095

14. Blankenbaker DG, de Smet AA, Keene JS. Sonography of the iliopsoas tendon and injection of the iliopsoas Bursa for diagnosis and management of the painful snapping hip. Skeletal Radiol. 2006;35(8):565-571. doi:10.1007/s00256-006-0084-6

15. Flanum ME, Keene JS, Blankenbaker DG, DeSmet AA. Arthroscopic treatment of the painful "internal" snapping hip: Results of a new endoscopic technique and imaging protocol. Am J Sports Med. 2007;35(5):770-779. doi:10.1177/0363546506298580

16. Ross JR, Larson CM, Bedi A. Indications for Hip Arthroscopy. Sports Health. 2017;9(5):402-413. doi:1 $0.1177 / 1941738117712675$

17. Flato R, Passanante GJ, Skalski MR, Patel DB, White EA, Matcuk GR Jr. The iliotibial tract: imaging, anatomy, injuries, and other pathology. Skeletal Radiol. 2017;46(5):605-622. doi:10.1007/s00256-01 7-2604-y

18. Byrd JWT. Evaluation of the hip: history and physical examination. North American journal of sports physical therapy: NAJSPT. 2007;2(4):231-240. Accessed June 9, 2021. http://www.ncbi.nlm.nih.gov/ pubmed/21509142

19. Bureau NJ. Sonographic Evaluation of Snapping Hip Syndrome. Journal of Ultrasound in Medicine. 2013;32(6):895-900. doi:10.7863/ultra.32.6.895

20. Keskula DR, Lott J, Duncan JB. Snapping Iliopsoas Tendon in a Recreational Athlete: A Case Report. Journal of Athletic Training. 1999;34(4):382-385. Accessed January 2, 2021. https://www.nata.org/jat

21. Kim CH, Lee SK, Kim JH, Yoon PW. External snapping hip: classification based on magnetic resonance imaging features and clinical correlation. HIP International. Published online July 23, 2020. do i:10.1177/1120700020944139

22. Henning PT. The Running Athlete: Stress Fractures, Osteitis Pubis, and Snapping Hips. Sports Health. 2014;6(2):122-127. doi:10.1177/194173811452 $\underline{3381}$ 
23. Grumet RC, Frank RM, Slabaugh MA, Virkus WW, Bush-Joseph CA, Nho SJ. Lateral hip pain in an athletic population: Differential diagnosis and treatment options. Sports Health. 2010;2(3):191-196. doi:10.1177/1941738110366829

24. Tyler TF, Nicholas SJ. Rehabilitation of extraarticular sources of hip pain in athletes. NAJSPT. 2007;2(4):207-216. Accessed January 2, 2021. http://w ww.ncbi.nlm.nih.gov/pubmed/21509140

25. Yen YM, Lewis CL, Kim YJ. Understanding and treating the snapping hip. Sports Medicine and Arthroscopy Review. 2015;23(4):194-199. doi:10.1097/i $\underline{\text { sa.0000000000000095 }}$

26. Baker CL Jr, Massie RV, Hurt WG, Savory CG. Arthroscopic Bursectomy for Recalcitrant Trochanteric Bursitis. Arthroscopy. 2007;23(8):827-832. doi:10.1016/j.arthro.2007.02.015

27. Farr D, Selesnick H, Janecki C, Cordas D. Arthroscopic Bursectomy With Concomitant Iliotibial Band Release for the Treatment of Recalcitrant Trochanteric Bursitis. Arthroscopy. 2007;23(8):905.e1-905.e5. doi:10.1016/j.arthro.2006.1 $\underline{0.021}$

28. Plastaras CT, Rittenberg JD, Rittenberg KE, Press J, Akuthota V. Comprehensive functional evaluation of the injured runner. Physical Medicine and Rehabilitation Clinics of North America. 2005;16(3):623-649. doi:10.1016/j.pmr.2005.02.005

29. Giai Via A, Basile A, Wainer M, Musa C, Padulo J, Mardones R. Endoscopic release of internal snapping hip: A review of literature. MLTJ. 2016;6(3):372-377. $\underline{\mathrm{d}}$ oi:10.11138/mltj/2016.6.3.372

30. Spina AA. External coxa saltans (snapping hip) treated with Active Release Techniques: a case report. The Journal of the Canadian Chiropractic Association. 2007;51(1):23-29. Accessed June 9, 2021. http://ww w.ncbi.nlm.nih.gov/pubmed/17657288

31. Adler RS, Buly R, Ambrose R, Sculco T. Diagnostic and Therapeutic Use of Sonography-Guided Iliopsoas Peritendinous Injections. American Journal of Roentgenology. 2005;185(4):940-943. doi:10.2214/ajr.0 $\underline{4.1207}$

32. Jacobson JA, Bedi A, Sekiya JK, Blankenbaker DG. Evaluation of the Painful Athletic Hip: Imaging Options and Imaging-Guided Injections. American Journal of Roentgenology. 2012;199(3):516-524. doi:1 $\underline{0.2214 / a j r .12 .8992}$
33. Zhu Z, Zhang J, Sheng J, Zhang C, Xie Z. Low back pain caused by iliopsoas tendinopathy treated with ultrasound-guided local injection of anesthetic and steroid: A retrospective study. JPR.

2020;13:3023-3039. doi:10.2147/jpr.s281880

34. Torriani M, Souto SCL, Thomas BJ, Ouellette H, Bredella MA. Ischiofemoral Impingement Syndrome: An Entity With Hip Pain and Abnormalities of the Quadratus Femoris Muscle. American Journal of Roentgenology. 2009;193(1):186-190. doi:10.2214/ajr.0 $\underline{8.2090}$

35. Cohen SP, Narvaez JC, Lebovits AH, Stojanovic MP. Corticosteroid injections for trochanteric bursitis: Is fluoroscopy necessary? A pilot study. British Journal of Anaesthesia. 2005;94(1):100-106. doi:10.1093/bja/a ei012

36. Cohen SP, Strassels SA, Foster L, et al. Comparison of fluoroscopically guided and blind corticosteroid injections for greater trochanteric pain syndrome: Multicentre randomised controlled trial. BMJ. 2009;338(7701):986-988. doi:10.1136/bmj.b1088

37. Ilizaliturri VM, Camacho-Galindo J. Endoscopic treatment of snapping hips, iliotibial band, and iliopsoas tendon. Sports Medicine and Arthroscopy Review. 2010;18(2):120-127. doi:10.1097/isa.0b013e31 $\underline{81 \mathrm{dc} 57 \mathrm{a} 5}$

38. Polesello GC, Queiroz MC, Domb BG, Ono NK, Honda EK. Surgical technique: Endoscopic gluteus maximus tendon release for external snapping hip syndrome hip. Clinical Orthopaedics \& Related Research. 2013;471(8):11999-11012. doi:10.1007/s119 99-012-2636-5

39. Hung CY, Chang KV, Özçakar L. Snapping Hip due to Gluteus Medius Tendinopathy: Ultrasound Imaging in the Diagnosis and Guidance for Prolotherapy. Pain Med. 2015;16(10):2040-2041. doi:10.1111/pme.12813

40. White RA, Hughes MS, Burd T, Hamann J, Allen WC. A new operative approach in the correction of external coxa saltans: The snapping hip. Am J Sports Med. 2004;32(6):1504-1508. doi:10.1177/0363546503 $\underline{262189}$

41. Ilizaliturri VM Jr, Martinez-Escalante FA, Chaidez PA, Camacho-Galindo J. Endoscopic Iliotibial Band Release for External Snapping Hip Syndrome. Arthroscopy. 2006;22(5):505-510. doi:10.1016/j.arthr o.2005.12.030

42. Randelli F, Mazzoleni MG, Fioruzzi A, Giai Via A, Calvisi V, Ayeni OR. Surgical interventions for external snapping hip syndrome. Knee Surg Sports Traumatol Arthrosc. Published online October 16, 2020. doi:10.1007/s00167-020-06305-w 
43. Malinowski K, Kalinowski Ł, Góralczyk A, Ribas M, Lund B, Hermanowicz K. External Snapping Hip Syndrome Endoscopic Treatment: "Fan-like" Technique as a Stepwise, Tailor-made Solution. Arthroscopy Techniques. 2020;9(10):e1553-e1557. do i:10.1016/j.eats.2020.06.017

44. el Bitar YF, Stake CE, Dunne KF, Botser IB, Domb BG. Arthroscopic iliopsoas fractional lengthening for internal snapping of the hip: Clinical outcomes with a minimum 2-year follow-up. Am J Sports Med. 2014;42(7):1696-1703. doi:10.1177/036354651453103 7

45. Ilizaliturri VM Jr, Villalobos FE Jr, Chaidez PA, Valero FS, Aguilera JM. Internal snapping hip syndrome: Treatment by endoscopic release of the iliopsoas tendon. Arthroscopy. 2005;21(11):1375-1380. doi:10.1016/j.arthro.2005.0 $\underline{8.021}$

46. Chang KV, Wu WT, Özçakar L. Ultrasound imaging and guided hydrodilatation for the diagnosis and treatment of internal snapping hip syndrome. Kaohsiung Journal of Medical Sciences. 2019;35(9):582-583. doi:10.1002/kjm2.12081

47. Hwang DS, Hwang JM, Kim PS, et al. Arthroscopic treatment of symptomatic internal snapping hip with combined pathologies. Clin Orthop Surg. 2015;7(2):158. doi:10.4055/cios.2015.7.2.158

48. Patel KA, Chhabra A, Goodwin JA, Brown JC, Hartigan DE. Arthroscopic Iliopsoas Release at the Level of the Lesser Trochanter Following Total Hip Arthroplasty. Arthroscopy Techniques. 2017;6(4):e1421-e1426. doi:10.1016/j.eats.2017.05.02 3

49. Ilizaliturri VM Jr, Chaidez C, Villegas P, Briseño A, Camacho-Galindo J. Prospective Randomized Study of 2 Different Techniques for Endoscopic Iliopsoas Tendon Release in the Treatment of Internal Snapping Hip Syndrome. Arthroscopy. 2009;25(2):159-163. doi:10.1016/i.arthro.2008.08.009

50. Ilizaliturri VM Jr, Buganza-Tepole M, Olivos-Meza A, Acuna M, Acosta-Rodriguez E. Central compartment release versus lesser trochanter release of the iliopsoas tendon for the treatment of internal snapping hip: A comparative study. Arthroscopy. 2014;30(7):790-795. doi:10.1016/j.arthro.2014.03.008

51. Maldonado DR, Lall AC, Battaglia MR, Laseter JR, Chen JW, Domb BG. Arthroscopic Iliopsoas Fractional Lengthening. JBJS Essential Surgical Techniques. 2018;8(4):e30. doi:10.2106/ibjs.st.18.00020
52. Villanueva M, Iborra Á, Sanz-Ruiz P, Noriega C. Ultrasound-guided surgery for lateral snapping hip: a novel ultraminimally invasive surgical technique. $J$ Orthop Surg Res. 2021;16(1):322. doi:10.1186/s1301 8-021-02461-y

53. Pierce TP, Kurowicki J, Issa K, Festa A, Scillia AJ, McInerney VK. External snapping hip: a systematic review of outcomes following surgical intervention: External snapping hip systematic review. HIP International. 2018;28(5):468-472. doi:10.1177/11207 $\underline{00018782667}$

54. Khan M, Adamich J, Simunovic N, Philippon MJ, Bhandari M, Ayeni OR. Surgical management of internal snapping hip syndrome: A systematic review evaluating open and arthroscopic approaches. Arthroscopy. 2013;29(5):942-948. doi:10.1016/j.arthr o.2013.01.016

55. Potalivo G, Bugiantella W. Snapping hip syndrome: Systematic review of surgical treatment. HIP International. 2017;27(2):111-121. doi:10.5301/hi pint. 5000464

56. Larsen E, Johansen J. Snapping hip. Acta Orthopaedica. 1986;57(2):168-170. doi:10.3109/17453 $\underline{678609000894}$

57. Zoltan DJ, Clancy WG Jr, Keene JS. A new operative approach to snapping hip and refractory trochanteric bursitis in athletes. Am J Sports Med. 1986;14(3):201-204. doi:10.1177/03635465860140030 4

58. Provencher MT, Hofmeister EP, Muldoon MP. The Surgical Treatment of External Coxa Saltans (the Snapping Hip) by Z-plasty of the Iliotibial Band. Am J Sports Med. 2004;32(2):470-476. doi:10.1177/0363546 503261713

59. Faraj AA, Moulton A, Sirivastava VM. Snapping iliotibial band: Report of ten cases and review of the literature. Acta Orthopaedica Belgica. Published online 2001.

60. Brignall CG, Stainsby GD. The snapping hip. Treatment by Z-plasty. Journal of Bone and Joint Surgery. 1991;73-B(2):253-254. doi:10.1302/0301-620 x.73b2.2005149

61. Nam KW, Yoo JJ, Koo KH, Yoon KS, Kim HJ. A modified Z-plasty technique for severe tightness of the gluteus maximus. Scandinavian Journal of Medicine \& Science in Sports. 2011;21(1):1600. doi:1 0.1111/i.1600-0838.2009.01011.x 
62. Sayed-Noor AS, Pedersen E, Sjödèn GO. A new surgical method for treating patients with refractory external snapping hip: Pedersen-Noor operation. $J$ Surg Orthop Adv. 2012;21(03):132-135. doi:10.3113/js oa.2012.0132

63. Taylor GR, Clarke NM. Surgical release of the "snapping iliopsoas tendon." Journal of Bone and Joint Surgery. 1995;77-B(6):881-883. doi:10.1302/0301-620 X.77b6.7593099

64. Dobbs MB, Gordon JE, Luhmann SJ, Szymanski DA, Schoenecker PL. Surgical correction of the snapping iliopsoas tendon in adolescents. Journal of Bone and Joint Surgery. 2002;84-A(3):420-424. doi:1 $\underline{0.2106 / 00004623-200203000-00013}$
65. Hoskins JS, Burd TA, Allen WC. Surgical Correction of Internal Coxa Saltans. Am J Sports Med. 2004;32(4):998-1001. doi:10.1177/0363546503260066

66. Gruen GS, Scioscia TN, Lowenstein JE. The surgical treatment of internal snapping hip. Am J Sports Med. 2002;30(4):607-613. doi:10.1177/0363546 5020300042201

67. Komarasamy B, Vadivelu R, Kershaw CJ. Clinical outcome following a modified approach for psoas lengthening for coxa saltans in adults. HIP. 2007;17(3):150-154. doi:10.5301/hip.2008.5541 